\title{
p68 RNA Helicase: Identification of a Nucleolar Form and Cloning of Related Genes Containing a Conserved Intron in Yeasts
}

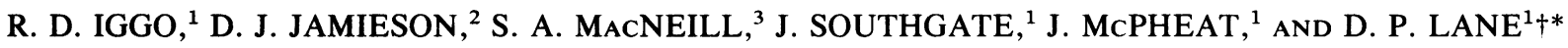 \\ Molecular Immunochemistry Laboratory, Imperial Cancer Research Fund Clare Hall Laboratories, South Mimms, \\ Herts, EN6 $3 L D,{ }^{1}$ Department of Molecular Biology, University of Edinburgh, Edinburgh, EH9 $3 J R,^{2}$ \\ and Imperial Cancer Research Fund Cell Cycle Group, Department of Biochemistry, \\ University of Oxford, Oxford, OXI $3 Q U,{ }^{3}$ United Kingdom
}

Received 1 October 1990/Accepted 4 December 1990

\begin{abstract}
The human p68 protein is an RNA-dependent ATPase and RNA helicase which was first identified because of its immunological cross-reaction with a viral RNA helicase, simian virus $\mathbf{4 0}$ large $T$ antigen. It belongs to a recently discovered family of proteins (DEAD box proteins) that share extensive regions of amino acid sequence homology, are ubiquitous in living organisms, and are involved in many aspects of RNA metabolism, including splicing, translation, and ribosome assembly. We have shown by immunofluorescent microscopy that mammalian p68, which is excluded from the nucleoli during interphase, translocates to prenucleolar bodies during telophase. We have cloned $55 \%$ identical genes from both Schizosaccharomyces pombe and Saccharomyces cerevisiae and shown that they are essential in both yeasts. The human and yeast genes contain a large intron whose position has been precisely conserved. In $S$. cerevisiae, the intron is unusual both because of its size and because of its location near the $3^{\prime}$ end of the gene. We discuss possible functional roles for such an unusual intron in an RNA helicase gene.
\end{abstract}

Manipulation of RNA secondary structure is essential for the proper execution of a large number of processes in the cell. The importance that the cell attaches to this problem has only recently come to light with the discovery of a large family of proteins with putative ATP-dependent RNA helicase activity. These proteins are readily identified because they all possess a core region of highly conserved motifs in their primary amino acid sequences. One of the most conserved motifs is the DEAD box (LDEADxxL), which gives the family its name (34). DEAD box proteins form a subset of a more loosely defined family, identified by Hodgman (27) and Gorbalenya et al. (21), of proteins with known or putative helicase activity.

RNA helicase activity has been demonstrated in vitro for only two DEAD box proteins: p68 (26), in which the DEAD motifs were first identified (18), and eIF4A (44), a translation initiation factor. Although the biological processes in which the other members are involved may prove very diverse, it seems reasonable to expect that all of them will show RNA helicase activity, at least in strand displacement assays in vitro. The family appears to be very large, since DEAD box proteins have been found in all prokaryotes and eukaryotes examined, and even the relatively small genome of Saccharomyces cerevisiae contains genes encoding at least 12 different members (TIF1 and -2 [35], MSS116 [49], SPB4 [46], PRP5 [11], PRP28 [52a], DEDI [42a], DBP1 [29a], $D B P 2$ [this report], and CA3, CA4, and CA5/6 [7]).

We are interested in p68 because of its specific immunological cross-reaction with the simian virus $\mathbf{4 0}$ large $\mathrm{T}$ antigen (31). We have taken two approaches to determine the function of p68. First, we have used immunofluorescent microscopy and antibody microinjection to study the cell biology of p68 in mammalian cells. Using antibodies to

\footnotetext{
* Corresponding author.

$\dagger$ Present address: Department of Biochemistry, The University, Dundee, DD1 4HN, United Kingdom.
}

nucleolar antigens, we show that p68 is transiently associated with the nucleoli during late telophase, at the time when prenucleolar bodies are condensing after mitosis. Antibodies to p68 microinjected into the cell cytoplasm are specifically transported to the nucleoli, although they do not grossly disrupt cell growth. Second, by cloning related genes from Schizosaccharomyces pombe and Saccharomyces cerevisiae, we show that both the deduced amino acid sequence and the gene structure of p68 have been highly conserved in evolution. Gene disruption demonstrates that the yeast genes are essential for viability in both yeast species.

\section{MATERIALS AND METHODS}

Cell staining. C6 cells were provided by M. Oren, 293 cells were provided by $\mathrm{P}$. Gallimore, and CV1, 3T3, and HFF cells were provided by Imperial Cancer Research Fund cell production. Antinucleophosmin monoclonal antibody hybridoma supernatant (41) was provided by P. K. Chan. PAb204 (anti-p68), BG2 (anti- $\beta$-galactosidase), and CAT2 (anti-chloramphenicol acetyltransferase) monoclonal antibodies were prepared in this laboratory. Human antinuclear antibody (nucleolar pattern: ANA-N) was purchased from Sigma. For immunofluorescent microscopy, cells were fixed for $5 \mathrm{~min}$ in acetone-methanol. Primary antibodies were visualized with commercial fluorescein- and rhodamineconjugated anti-immunoglobulin sera except for the cells shown in Fig. 1C (biotinylated PAb204 plus streptavidinfluorescein), 2E (biotinylated PAb204 plus streptavidinTexas red), and $2 \mathrm{~F}$ (directly conjugated CAT2-fluorescein).

Affinity-purified anti-p68 immunoglobulin was prepared by acid elution from a p68 column of serum from a rabbit (MF6) immunized with a gel-purified bacterially expressed $p 68 / \beta$ galactosidase fusion protein. The p68 column was made by incubating HeLa cell extract with PAb204 (28) and immobilizing the immune complexes on a rabbit anti-mouse immunoglobulin column by coupling with dimethyl pimelidate. The rabbit anti-mouse immunoglobulin column was prepared 
by reacting Dako rabbit anti-mouse immunoglobulins with Pharmacia cyanogen bromide-activated Sepharose 4B. PAb204 leakage from the column can be ruled out because a peptide corresponding to the PAb204/p68 epitope (18) abolishes immunofluorescent cell staining with PAb204 but has no effect on affinity-purified MF6 staining.

Microinjection. PAb204 was purified from serum-free hybridoma supernatant by chromatography on protein A-Sepharose in the presence of $3.3 \mathrm{M} \mathrm{NaCl}(23)$. BG2 was purified from monoclonal ascites fluid by chromatography on a rabbit anti-mouse immunoglobulin column (23). Antibody at $10 \mathrm{mg} / \mathrm{ml}$ was injected in buffer containing $57 \mathrm{mM} \mathrm{KCl}$, $7.5 \mathrm{mM} \mathrm{NaCl}, 2.75 \mathrm{mM} \mathrm{MgCl}{ }_{2}$, and $5 \mathrm{mM}$ Tris (pH 7.0). Cells in $N$-2-hydroxyethylpiperazine- $N^{\prime}$-2-ethanesulfonic acid (HEPES)-buffered Dulbecco modified Eagle medium maintained at $35^{\circ} \mathrm{C}$ on a heated microscope stage were injected under phase contrast, using a Zeiss model MR micromanipulator and an Eppendorf model 5242 microinjector.

Transfection. 293 cells were transfected with pCIS5p68, which contains a full-length human p68 cDNA clone under the control of the cytomegalovirus major immediate-early promoter, using the method of Gorman et al. (22). To distinguish endogenous from transfected p68, cells were cotransfected with pCIS-CAT (which contains the chloramphenicol acetyltransferase gene under the control of the immediate-early promoter) and identified by double labeling with CAT2 and PAb204. Control transfections with pCISCAT alone showed that expression of chloramphenicol acetyltransferase does not alter the pattern of endogenous p68 staining. pCIS5 and pCIS-CAT (22) were kindly supplied by C. Gorman.

DNA cloning. General cloning techniques were performed as described by Sambrook et al. (47). The Fickett analysis in Fig. 5 was done by using the University of Wisconsin Genetics Computer Group program Testcode with a window of $300 \mathrm{bp}(14,16)$. To map $D B P 2, S$. cerevisiae chromosomes were resolved by using a CHEF-DRII gel system (Bio-Rad), Southern blotted, and hybridized to a $D B P 2$ probe spanning nucleotides 928 to 2242 .

Disruption. Deletion of the $S$. pombe $d b p 2$ and $S$. cerevisiae $D B P 2$ genes was accomplished by one-step gene replacement (43). The $S$. cerevisiae URA3 gene was cloned into the EcoRV and $B g l \mathrm{II}$ sites of $D B P 2$ (between amino acids 375 and 497). A Ball fragment (from nucleotide 963 to a $B a l$ site $0.7 \mathrm{~kb}$ downstream of the $B g$ lII site) was gel purified and transformed into DJY84 (a MATa/ $\alpha$ ura3-52/

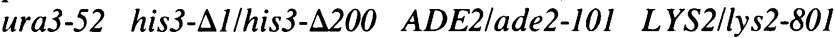
trpl-289/trpl- $\Delta 1$ leu2-3,112/LEU2 strain) by the lithium acetate technique (29). Stable diploid $\mathrm{Ura}^{+}$colonies were picked and analyzed by polymerase chain reaction (PCR) (from a $D B P 2$ primer [CTCAACCATTATTGGCTCCAG] to a $U R A 3$ primer [GGTAGAGGGTGAACGTTACAG]) and Southern blotting to identify transformants in which one copy of $D B P 2$ had been disrupted. Cells from the strain (DJY98) containing the disruption were sporulated, and tetrads were dissected and allowed to germinate on YPD plates (50). To demonstrate rescue of the inviable spores by $D B P 2$, a full-length $D B P 2$ cDNA (from nucleotides 61 to 2776) under the control of the $G A L I$ promoter on a $C E N /$ ARS/TRPI plasmid was transformed into diploid DJY98 cells. This strain was then sporulated, and tetrads were dissected as described above, analyzed for uracil prototrophy (indicating the presence of a disrupted chromosomal copy of $D B P 2$ ) and tryptophan prototrophy (indicating the presence of the plasmid copy of the $D B P 2$ cDNA), and subjected to PCR to confirm the integrity of the recombinant DNA molecules in the recovered strains.

The $S$. pombe $d b p 2$ gene (nucleotides 187 to 2648) with the $S$. pombe ura4 gene inserted between the MluI and AfII sites (from amino acid 205 to a position within the intron) was cloned into the EcoRV site of Bluescript (Stratagene); $\sim 10 \mu \mathrm{g}$ of insert DNA (from the BamHI to SalI sites in Bluescript) was gel purified and transformed by the method of Beach and Nurse (1) into a leul-32/leul-32 ura4-D18/ura4D18 ade6-M210/ade6-M216 $h^{+} / h^{-}$strain (40). Following 7 days of growth on minimal medium plus leucine, stable diploid $\mathrm{Ura}^{+}$transformant colonies were picked and analyzed by PCR (from a $d b p 2$ primer [AACCCTTGTAAACC TCAAAATTACC] to a ura 4 primer [CCACAAATTCATGT TTGGACT]) to identify transformants in which $d b p 2$ had been partially deleted as intended. Diploids containing the deletion were sporulated on malt extract medium, and tetrads were dissected by using a micromanipulator (40).

Nucleotide sequence accession numbers. The nucleic acid sequences (including complete sequences for the intron shown in Fig. 4) have been deposited in the EMBL data base under accession numbers X15729 (human), X52648 ( $S$. pombe), and X52649 (S. cerevisiae).

\section{RESULTS}

p68 is present in prenucleolar bodies. We have previously reported that mammalian p68 shows dramatic changes in nuclear location during the cell cycle (28). Double-label immunofluorescent cell staining with anti-p68 and antinucleolar antibodies (Fig. 1) shows that the densely staining structures seen with PAb204 during telophase are prenucleolar bodies. This is in contrast with the distribution during interphase, when p68 is present in the nucleoplasm and excluded from the nucleoli. Nucleophosmin is an abundant protein in the granular component of the interphase nucleolus (52). Although nucleophosmin is detectable in prenucleolar bodies by electron microscopy (42), it is not seen by light microscopy until early $\mathrm{G}_{1}$ (41). Double labeling of acetone-methanol-fixed cells shows that there is very little overlap between the p68 and nucleophosmin staining patterns: nucleolar PAb204 staining is at its most intense when the majority of nucleophosmin is in the cytoplasm (Fig. 1C and D).

The proliferating cell nuclear antigen gives transient S-phase nucleolar staining (5), apparently as a result of masking of the dominant epitope on the proliferating cell nuclear antigen in the nucleolus during the rest of the cell cycle (55). To establish whether the cell cycle variation in p68 staining reflects epitope masking or bulk movement of p68, we repeated the staining with affinity-purified anti-p68 serum (MF6) depleted of antibodies to the PAb204 epitope. Affinity-purified MF6 stains prenucleolar bodies in an identical manner to PAb204 (Fig. $1 \mathrm{E}$ to $\mathrm{H}$ ), suggesting that the cell cycle changes are not simply a result of epitope masking.

Microinjection of PAb204. The strong conservation of the PAb204 epitope, both across species and between p68 and simian virus $40 \mathrm{~T}$ antigen, suggests that it may be part of a protein- or RNA-binding site (28). According to this model, microinjection of PAb204 antibody should significantly interfere with p68's normal function. In practice, 3T3, HFF, C6, and CV1 cells all continue to grow and divide apparently normally following injection (Fig. $2 \mathrm{~A}$ and $\mathrm{C}$ ). The antibody was injected into the cytoplasm but should have gained free access to nuclear p68 molecules following nuclear envelope breakdown at mitosis. Even in postmitotic cells, antibody 

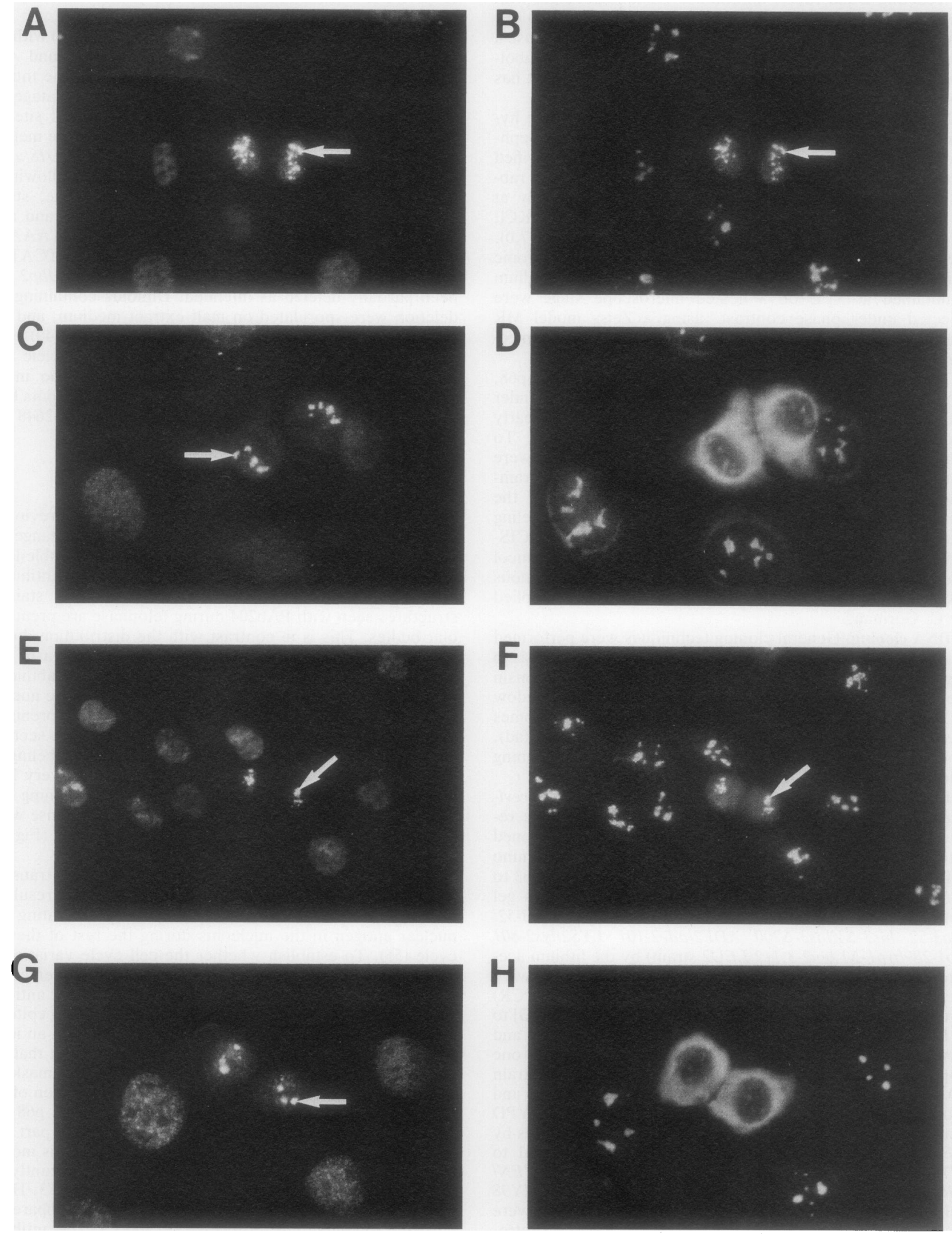

FIG. 1. Double-label immunofluorescence showing anti-p68 (A, C, E, and G) and antinucleolar (B, D, F, and H) staining of C6 cells. (A and C) PAb204; (E and G) MF6; (B and F) ANA-N; (D and H) antinucleophosmin. Prenucleolar bodies are marked with arrows. Magnifications: A, B, E, and F, $\times 375 ; \mathrm{C}, \mathrm{D}, \mathrm{G}$, and $\mathrm{H}, \times 590$. 

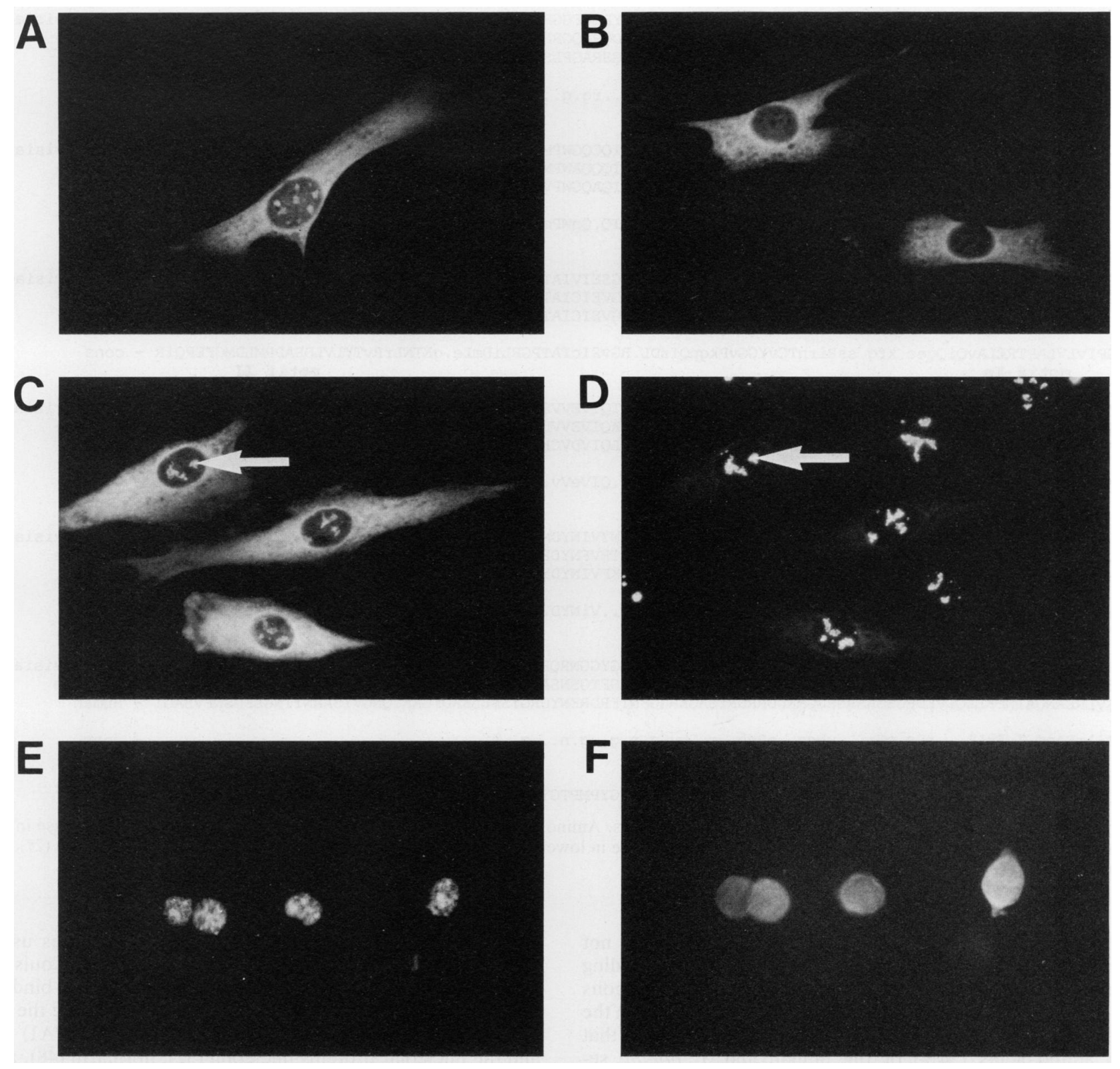

FIG. 2. Microinjection of PAb204 (A, C, and D) and BG2 (B) into 3T3 (A and B) and C6 (C and D) cells fixed after $24 \mathrm{~h}$ and stained with rhodamine-conjugated anti-mouse immunoglobulin (A to C) and ANA-N (D; same field as in panel C). Nucleolar staining in panels C and D is marked with arrows. Double label of 293 cells transfected with a p68 overexpression construct: (E) PAb204; (F) CAT2 (a marker for transfected cells). Magnifications: A, B, E, and F, $\times 330 ; \mathrm{C}$ and D, $\times 375$.

never accumulated to high levels in the nucleoplasm, although p68 could still be detected there by double labeling (data not shown). In the three fibroblast cell lines, PAb204 was transported to the nucleoli following injection into the cytoplasm (Fig. 2C and D). This is not an artifact because it could be seen in living cells injected with directly labeled antibody (data not shown) and was not seen with control antibodies (Fig. 2B). The nucleolar staining was only seen in cells that had divided. One possible explanation is that $\mathrm{p} 68$ enters the nucleus only at mitosis. This is unlikely because transfected p68 expressed from an exogenous promoter readily enters the nucleus, with no cytoplasmic accumulation in interphase cells (Fig. 2E and F).
Cloning of yeast genes related to p68. To permit genetic analysis of p68's function, we sought yeast homologs by low-stringency screening of yeast $\lambda$ gt 11 libraries (38). We obtained two identical $S$. cerevisiae genomic clones, both of which start within a 1-kb intron, and four $S$. pombe cDNA clones, of which three are identical and the fourth encodes the same open reading frame interrupted by a 700-bp intron. Full-length clones were obtained by a combination of library and PCR techniques and shown to be single-copy genes by Southern blotting of genomic DNA (data not shown). We call the genes $d b p 2(S$. pombe) and $D B P 2$ ( $S$. cerevisiae), for DEAD box protein 2. Southern blots of $S$. cerevisiae chromosomes resolved by pulsed-field gel electrophoresis 
MTYGGRDOOYNKTNYKSRGGDFRGGRNSDRNSYNDRPOGGNYRGGFGGRSNYNOPOELIKPNWDEELPKLPTFEKNFYVEHESVRDRS - S. CEIEV I S I Ae MSYRDNEYSGNYNGKEDGYNSRGRYGGGYRNNYSRGGGRGGFNDGASYGYDQRGQGRNFYESDGPGANLVKKDWKNETLIPFOKDFYKEHENVRNRS - S. POIBE MSGYSSDRDRGRDRGFGAPRFGGSRAGPLSGKKFGNPGEKLVKKKWNLDELPKFEKNFYQEHPDLARRT - Human

....sr...r...ndga..g...rg.g......pg..lvkkdw.l..Lp.FeKnFY.EHe.vr.Rs - cons

DSEIAOFRKENEMTISGHDIPKPITTFDEAGFPDYVLNEVKAEGFDKPTGIQCQGWPMALSGRDMVGIAATGSGKTLSYCLPGIVHINAQPLIAPGD - S. CEIEVISI AE DAEVTEYRKTKEIVVHGLNVPKPVTTFEEAGFPNYVLKEVKOLGFEAPTPIOOOAWPMAMSGRDMVGISATGSGKTLSYCLPAIVHINAOPLLSPGD - S. POMBE AQEVETYRRSKEITVRGHNCPKPVINFYEANFPANVMDVIARQNFTEPTAIQAQGWPVALSGLDMVGVAQTGSGKTLSYLIPAIVHINHQPFLERGD - HUMAI

d.Ev. .yRkekE1tv.Ghn.PKPvttF.EAgFP.yVl.evk..gF..PT.IQ.QgNPMAISGrDMVGIaaTGSGKTLSYCLPaIVHINaQPIL.pGD - CONS motif I

GPIVLVLAPTREIAVQIOTECSKFGHSSRIRNTCVYGGVPKSOQIRDLSRGSEIVIATPGRLIDMLEIGKTNLKRVTYLVLDEADRMLDMGFEPOIR - S. CEIEVISI AE GPIVLVLAPTRELAVQIQOECTKFGKSSRIRNTCVYGGVPLGPQILDLIRGVEICIATPGRLIDMIDSNKTNLRRVTYLVLDEADRMLDMGFEPQIR - S.POMBE GPICLVLAPTRELAQQVQQVAAEYCRACRLKSTCIYGGAPKGPQIRDLERGVEICIATPGRLIDFLECGKTNLRRTTYLVLDEADRMLDMGFEPQIR - HUMA

GPIVLVLAPTRELAVQIQqec. $\mathrm{kfg.sSRIrnTCVYGGvPkgPQIrDL.RGVEICIATPGRLIDmLe.gKTNLFRVTYLVLDEADRMLDMGFEPQIR} \mathrm{-} \mathrm{CONS}$ motif Ia motif II

KIVDOIRPDROTLMASATWPKEVKOLAADYINDPIOVOVGSLELSASHNITOIVEVVSDFEKRDRLNKYLETASODNEYKTLIFASTKRMCDDITKY - S. CE EV I SI AE KIVDOIRPDROTVMFSATWPKEVORIARDYINDYIOVIVGSLDIAASHNIKOIVEVVDNADKRARLGKDIEEVLKDRDNKVIIFTGTKRVADDITRF - S.POMBE KIVDQIRPDRQTLMNSATWPKEVRQLAEDFLKDYIHINIGALELSANENILQIVDVCHDVEKDEKLIRIMEEIMSEKENKTIVFVETKRRCDELTRK - HUMA

KIVDQIRPDRQTIMWSATWPKEV.qLA.DYLNDYIqv.vGsLeLSAsHNI.QIVeVv.d.eKr.rL.k..Ee...d.enK.liF..TKR.cDdiTr. - CONS motif III motif IV

IREDGWPALAIHGDKDQRERDWVLOEFRNGRSPIMVATDVAARGIDVKGINYVINYDMPGNIEDYVHRIGRTGRAGATGTAISFFTEQNKGLGAKLI - S. Ce EVISI Ae LRODGWAIAIHGDKAODERDWVLNEFRTGKSPIMVATDVASRGIDVKGITHVFNYDFPGNTEDYVHRIGRTGRAGAKGTAYTYFTSDNAKOARELV - S. POMbE MRRDGWPAGIHGDKSQQERDWVLNEFKHGKAPILIATDVASRGLDVEDVKFVINYDYPNSSEDYIHRIGRTARSTKTGTAYTFFTPNNIKQVSDLI - HUMAN

1R.DGWPALAIHGDK.Q.ERDWVLnEFr.GkSPImVATDVASRGIDVkgi..ViNYD.Pgn.EDYvHRIGRTgRagatGTAYtfFT..N.kq...Li - CONS motif $V$ motif VI

SIMREANONIPPELLKYDRRSYGGGHPRYGGGRGGRGGYGRRGGYGGGRGGYGGNRQRDGGWGNRGRSNY

- S.cerevisiae SILSEAKODIDPKLEEMARYSSGGRGGNYRRGGYGRGGFRRGGGYGNRNRGFTGSNSAPLARSRM

- S.pombe SVLREANQAINPKLIOLVEDRGSGRSRGRGGMKDDRRDRYSAGKRGGFNTFRDRENYDRGYSSLLKRDFGAKTQNGVYSAANYTNGSFGSNFVSAGI - HUMAI

SilrEAnQ. I.PkLl ...r.s.gGr...yggg..gRgg..r.GgyGg.n.g..g.n...g..s..

- cons

QTSFRTGNPTGTYQNGYDSTQQYGSNVPNMHNGMNQQAYAYPATAAAPMIGYPMPTGYSQ

- Human

FIG. 3. Amino acid alignment of the human and yeast genes. Amino acids identical in all three sequences are shown in uppercase in the consensus (cons) line; those identical in only two sequences are in lowercase. Sequences matching the helicase motifs of Hodgman (27) and Gorbalenya et al. (21) are marked.

indicate that $D B P 2$ lies on chromosome XIII (data not shown). The yeast genes contain predicted open reading frames encoding $61-\mathrm{kDa}$ proteins that are homologous throughout their lengths, but the human gene differs from the yeast genes at both ends (Fig. 3). This analysis showed that 296 amino acids $(54 \%)$ of the human and $S$. pombe sequences, 301 amino acids (55\%) of the human and $S$. cerevisiae sequences, and 358 amino acids $(63 \%)$ of the $S$. pombe and $S$. cerevisiae sequences are identical, compared with $\sim 35 \%$ for the other members of the DEAD box family. The deduced carboxy termini of the yeast proteins contain the sequences YGGGHPRYGGGRGGRGGYGRRGGYGG GRGGYG GNR (DBP2) and GGRGGNYRRGGYGRGGFR
RGGGYGNRNRGF ( $d b p 2)$. PIR data base searches using the program PROSRCH (J. F. Collins and A. F. W. Coulson, University of Edinburgh) identified several RNA-binding proteins with related glycine-rich domains, including the A1 heterogeneous nuclear ribonucleoprotein (hnRNPA1) (9) and the nucleolar proteins nucleolin (32), fibrillarin (48), and yeast SSB1 (30). Among the DEAD box proteins, the Drosophila gene vasa $(25,33)$ contains a glycine-rich fivefold heptad repeat, F/SRGGE/QGG. Nucleolin, hnRNPA1, and SSB1 contain the RNP1 and RNP2 consensus RNA-binding domains (4), which are not present in p68, $D B P 2$, or $d b p 2$. Northwestern blotting (i.e., using RNA to probe a Western blot) of nucleolin fragments suggests that the RNP1 and

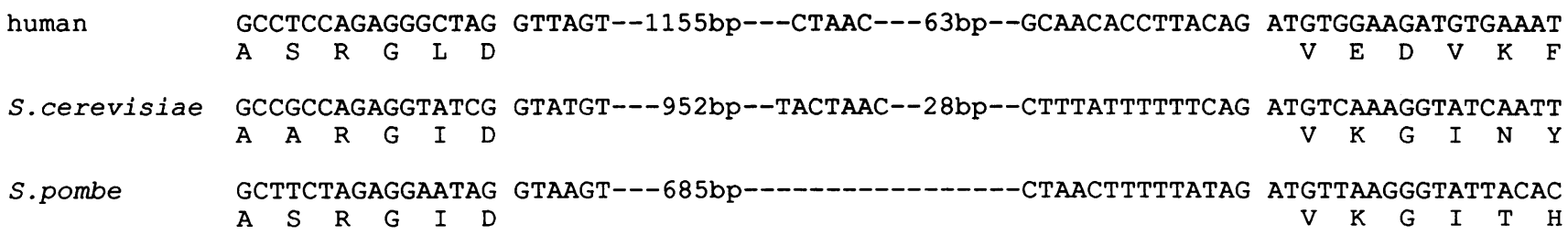

FIG. 4. Sequence comparison showing that human p68, $S$. pombe $d b p 2$, and $S$. cerevisiae $D B P 2$ contain an intron at the same site in helicase motif $\mathrm{V}$. The predicted human branchpoint sequence was identified by homology to the higher eukaryotic branchpoint consensus (YNRAY). 

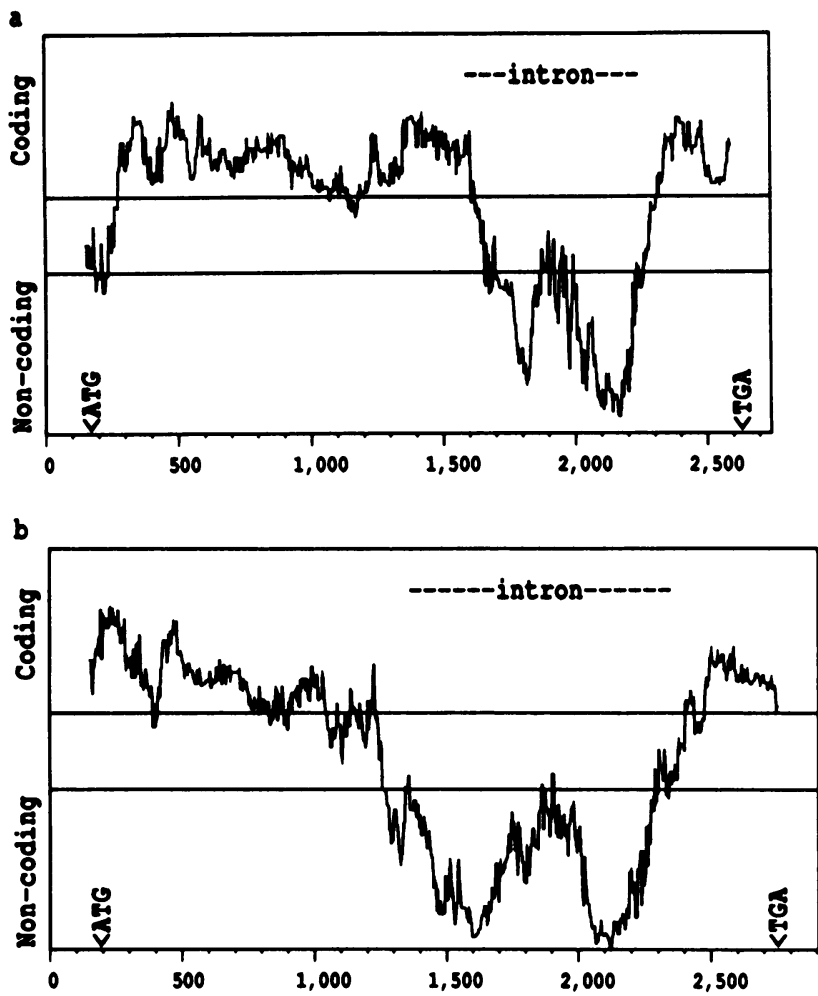

FIG. 5. Third-codon preference plots. (a) $S$. pombe $d b p 2$; (b) $S$. cerevisiae $D B P 2$. The assignment of coding regions for values of the test code statistic between the two horizontal lines is uncertain. Units on the $x$ axis are in base pairs.

RNP2 domains bind RNA but the glycine-rich domain does not (6). However, the high arginine and aromatic amino acid content of the glycine-rich domains may permit electrostatic and base stacking interactions which modify the specificity of nucleic acid binding (30).

Sequence analysis suggests that the PAb204 epitope (FR DRENYDRG in p68; PLDRLNFELGVAIDQFL in T antigen [18; unpublished data]) is not present in $D B P 2$ or $d b p 2$. We have confirmed the absence of the epitope from $d b p 2$ by immunoblotting of a $\beta$-galactosidase $/ d b p 2$ fusion protein with PAb204 (data not shown).

p68, $D B P 2$, and $d b p 2$ contain introns conserved from yeasts to humans. The p68, $D B P 2$, and $d b p 2$ genes all contain an intron at exactly the same position in motif $V$ (the ARGID motif; Fig. 3 and 4). The intron is $700 \mathrm{bp}$ long in $S$. pombe, $1 \mathrm{~kb}$ long in $S$. cerevisiae, and $1.2 \mathrm{~kb}$ long in humans. We identified an alternately spliced form of the human intron in one clone obtained from an Okayama-Berg library. The sequence of this cDNA is identical with that of the genomic DNA up to nucleotide 2428 , where an alternate $5^{\prime}$ splice site is used (CT/GTAAGG). This introduces a stop codon into the human sequence immediately after the prototypic $5^{\prime}$ splice site (nucleotide 1476). Translation of this variant would produce a truncated form of the p68 protein which would almost certainly be nonfunctional because it lacked part of motif V and all of motif VI. Many $S$. pombe genes contain small introns, although we identified none in the data base that contain an intron as large at that in $d b p 2$. We have identified no $S$. cerevisiae genes in the GenBank or EMBL data base that contain introns longer than the 551-bp intron in ribosomal protein S16A $(24,39)$ and only one intron near the $3^{\prime}$ end of a gene (the 52-bp second intron in MATal [37]). The intron in $D B P 2$ is thus remarkable both because of its size and because of its location near the $3^{\prime}$ end of the gene. One reason for conservation of an intron is the existence of an intron-encoded protein. However, the nucleotide sequences of the p68, $D B P 2$, and $d b p 2$ introns are not closely related, their deduced amino acid sequences contain no long open reading frames, and data base searches identify no closely related sequences (data not shown). Third-codon preference plots (16) strongly suggest that they are noncoding (Fig. 5).

$D B P 2$ and $d b p 2$ are essential genes. We disrupted the yeast genes by insertion of ura4 into $d b p 2$ and $U R A 3$ into $D B P 2$. Tetrad analysis of the disrupted strains revealed that only two out of four spores were viable and that all the surviving spores were $\mathrm{Ura}^{-}$. The $\mathrm{Ura}^{+}$spores germinated on schedule but arrested after about five rounds of cell division. Microscopic examination of the dying cells gave no clue to the function of $D B P 2$ or $d b p 2$. Specifically, the cells did not show a cell cycle arrest phenotype. To confirm that the effect in $S$. cerevisiae was due to disruption of the $D B P 2$ gene, we transformed the diploid $D B P 2 / D B P 2:: U R A 3$ strain with a $C E N / A R S$ plasmid encoding the $D B P 2$ cDNA under the control of the GAL1 promoter and repeated the tetrad analysis. In tetrads where the plasmid segregated with the disrupted $D B P 2$ allele, all four spores were viable, confirming that the inviability of DBP2::URA3 spores was due to the disruption and that $D B P 2$ is an essential gene.

\section{DISCUSSION}

We have demonstrated that p68 undergoes dramatic changes in nuclear location during the cell cycle, lying in the nucleoplasm during interphase and transiently entering the nucleoli during telophase. When the nucleolus re-forms at the end of mitosis, the first structures to appear are prenucleolar bodies, which contain mainly dense fibrillar components (54). Although these components are classically associated with rRNA processing (54), it is difficult to envisage p68 being directly involved in rRNA processing because anti-p68 antibodies do not stain the nucleoli of interphase cells. Perhaps p68 is required for an early step in nucleolar assembly.

There are many reasons why microinjected antibody might have no obvious effect: PAb204 may not bind to an essential site (it does not inhibit in vitro ATPase [28] or helicase [26] reactions), it may require many rounds of cell division to deplete the cell of p68's target, or the epitope may be masked on the majority of p68 molecules in living cells. The migration of antibody from the cytoplasm to the nucleoli is intriguing. Several models could account for this behavior: nucleolar shuttling (3), which is unlikely given the requirement for cell division; mitotic loading (2), which is unlikely given the failure of p68 to accumulate during interphase in the cytoplasm of transfected cells; or cell cycle-regulated synthesis of p68. The nuclear transport signal in p68 has not been identified experimentally, but the region between amino acids 32 and 45 (KK...KKK) is a likely candidate. Nucleolar transport signals $(12,51)$ resemble extended but otherwise unremarkable nuclear transport signals. Unless all nuclear proteins transit the nucleolus, for example to allow recycling of a nuclear transporter on the ribosomes, there seems no a priori reason why nucleolar targeting could not be achieved by entirely separate nuclear transport and nucleolar binding signals.

p68 is more closely related to $D B P 2$ and $d b p 2$ than it is to 
any other known DEAD box gene in yeasts (TIF1 and 2 [35], MSS116 [49], SPB4 [46], PRP5 [11], PRP28 [52a], DEDI [42a], DBP1 [29a], and CA3, CA4, and CA5/6 [7]). The major disagreement between p68 and the yeast $D B P 2$ and $d b p 2$ genes is at the carboxy terminus, which is the site of the PAb204 epitope (18). Since PAb204 does not recognize any proteins on Western blots of yeast whole-cell extract, it would have been surprising if the yeast genes had been homologous with p68 in this region. The absence of the PAb204 epitope from the yeast sequences and the presence of an extra 86 amino acids at the carboxy terminus of the human sequence argue for caution in equating p68 with the yeast genes that we cloned, which is why we have chosen to call them $D B P 2$ and $d b p 2$.

Of the $12 S$. cerevisiae DEAD box genes that have been identified so far (TIFI and 2 [35], MSSI16 [49], SPB4 [46], PRP5 [11], PRP28 [52a], DEDI [42a], DBPI [29a], DBP2 (this report), and CA3, CA4, and CA5/6 [7]), DBP2 is the only member of the family that contains an intron in motif $\mathrm{V}$. We recently learned of the existence of a Drosophila p68 homolog called RM62 (15) which also contains an intron in motif $\mathrm{V}(29 \mathrm{~b})$. The presence of an intron at the same site in the Drosophila gene vasa indicates that it is not unique to p68.

The evolutionary distance between $S$. cerevisiae and $S$. pombe is as great as the distance between yeasts and humans (45). We are aware of no other example of conservation of an intron in $S$. cerevisiae, $S$. pombe and humans. It implies that an ancestral intron was present at least 1.2 billion years ago, as has been postulated for the triosephosphate isomerase (TPI) introns in Aspergillus spp., chickens, and humans (20). Interestingly, the TPI introns may autoregulate TPI expression, since Manquat et al. $(8,10)$ have shown that premature termination of translation in exon 6 of human TPI mRNA reduces mRNA levels to $20 \%$ of normal and have speculated that translation past codon 189 facilitates splicing of TPI pre-mRNA. Few $S$. cerevisiae genes have introns, and in several cases those introns have specific functions: mitochondrial introns encode reverse transcriptases (36) and maturases and endonucleases (13); L32 prevents splicing of its own message by promoting base pairing between the $5^{\prime}$ end of the transcript and the $5^{\prime}$ splice site (53); and MATal contains two introns that are inefficiently spliced and may play a role in the gene conversion events during mating-type switching (17). $S$. pombe introns over $180 \mathrm{bp}$ are known to abolish splicing in a model system (19), but the existence of a 700-bp intron in $S$. pombe p68, which is an essential gene, indicates that this size limit does not operate in vivo. Although it is perhaps not surprising that one of the $S$. pombe clones was polyadenylated but unspliced, the fact that one of the human cDNA clones was alternately spliced suggests that splicing of the intron is subject to some form of physiological regulation. The unusual nature of the introns hints at the possibility of an intriguing form of autoregulation whereby an RNA helicase may control its own expression by modifying the secondary structure of its mRNA, a model that we are now in the process of testing experimentally in $S$. cerevisiae.

\section{ACKNOWLEDGMENTS}

We thank Iain Goldsmith for synthesis of oligonucleotides, Michelle Ginsburg for help with computing, Mike Goman for help with the CHEF blot, Alan Christensen, Evi Strauss, and John Pringle for communication of results prior to publication, and Paul Nurse and Jean Beggs for useful discussions.

D.J.J. is a Beit Memorial Fellow.

\section{REFERENCES}

1. Beach, D., and P. Nurse. 1981. High frequency transformation of the fission yeast Schizosaccharomyces pombe. Nature (London) 290:140-142.

2. Blow, J. J., and R. A. Laskey. 1988. A role for the nuclear envelope in controlling DNA replication within the cell cycle. Nature (London) 332:546-548.

3. Borer, R. A., C. F. Lehner, H. M. Eppenberger, and E. A. Nigg. 1989. Major nucleolar proteins shuttle between the nucleus and cytoplasm. Cell 56:379-390.

4. Brandziulis, R. J., M. S. Swanson, and G. Dreyfuss. 1989. RNA binding proteins as developmental regulators. Genes Dev. 3:431-437.

5. Bravo, R., S. J. Fey, J. Bellatin, P. M. Larsen, J. Arevalo, and J. E. Celis. 1981. Identification of a nuclear and of a cytoplasmic polypeptide whose relative proportions are sensitive to changes in the rate of cell proliferation. Exp. Cell Res. 136:311-319.

6. Bugler, B., H. Bourbon, B. Lapeyre, M. O. Wallace, J.-H. Chang, F. Amalric, and M. O. J. Olson. 1987. RNA binding fragments from nucleolin contain the ribonucleoprotein consensus sequence. J. Biol. Chem. 262:10922-10925.

7. Chang, T.-H., J. Arenas, and J. Abelson. 1990. Identification of five putative yeast RNA helicase genes. Proc. Natl. Acad. Sci. USA 87:1571-1575.

8. Cheng, J., M. Fogel-Petrovic, and L. E. Manquat. 1990. Translation to near the distal end of the penultimate exon is required for normal levels of spliced triosephosphate isomerase mRNA. Mol. Cell. Biol. 10:5215-5225.

9. Cobianchi, F., D. N. Sengupta, B. Z. Zmudzka, and S. H. Wilson. 1986. Structure of the rodent helix-destabilizing protein revealed by cDNA cloning. J. Biol. Chem. 261:3536-3543.

10. Daar, I. O., and L. E. Manquat. 1988. Premature translation termination mediates triosephosphate isomerase mRNA degradation. Mol. Cell. Biol. 8:802-813.

11. Dalbadie-McFarland, G., and J. Abelson. 1990. PRP5: a helicase-like protein required for mRNA splicing in yeast. Proc. Natl. Acad. Sci. USA 87:4236-4240.

12. Dang, C. V., and W. M. F. Lee. 1989. Nuclear and nucleolar targeting sequences of c-erb-A, c-myb, N-myc, p53, HSP70 and HIV tat proteins. J. Biol. Chem. 264:18019-18023.

13. Delahodde, A., V. Goguel, A. M. Becam, F. Creusot, J. Perea, J. Banroques, and C. Jacq. 1989. Site-specific DNA endonuclease and RNA maturase activities of two homologous intron-encoded proteins from yeast mitochondria. Cell 56:431-441.

14. Devereux, J., P. Haeberli, and O. Smithies. 1984. A comprehensive set of sequence analysis programs for the VAX. Nucleic Acids Res. 12:387-395.

15. Dorer, D. R., A. C. Christensen, and D. H. Johnson. 1990. A novel RNA helicase gene tightly linked to the triplo-lethal locus of Drosophila. Nucleic Acids Res. 18:5489-5494.

16. Fickett, J. W. 1982. Recognition of protein coding regions in DNA sequences. Nucleic Acids Res. 10:5303-5318.

17. Fink, G. R. 1987. Pseudogenes in yeast? Cell 49:5-6.

18. Ford, M. J., I. A. Anton, and D. P. Lane. 1988. Nuclear protein with sequence homology to translation initiation factor e1F4-A. Nature (London) 332:736-738.

19. Gaterman, K. B., A. Hoffiman, G. H. Rosenberg, and N. F. Kaufer. 1989. Introduction of functional artificial introns into the naturally intronless ura4 gene of Schizosaccharomyces pombe. Mol. Cell. Biol. 9:1526-1535.

20. Gilbert, W., M. Marchionni, and G. McKnight. 1986. On the antiquity of introns. Cell 46:151-153.

21. Gorbalenya, A. E., E. V. Koonin, A. P. Donchenko, and V. M. Blinov. 1989. Two related superfamilies of putative helicases involved in replication, recombination, repair and expression of DNA and RNA genomes. Nucleic Acids Res. 17:4713-4730.

22. Gorman, C., D. R. Gies, and G. McCray. 1990. Transient production of proteins using an adenovirus transformed cell line. DNA Protein Eng. Tech. 2:3-10.

23. Harlow, E. E., and D. P. Lane. 1988. Antibodies: a laboratory manual. Cold Spring Harbor Laboratory, Cold Spring Harbor, N.Y.

24. Hawkins, J. D. 1988. A survey on intron and exon lengths. 
Nucleic Acids Res. 16:9893-9908.

25. Hay, B., L. Y. Jan, and Y. N. Jan. 1988. A protein component of Drosophila polar granules is encoded by vasa and has extensive sequence similarity to ATP-dependent helicases. Cell 55:577-587.

26. Hirling, H., M. Scheffner, T. Restle, and H. Stahl. 1989. RNA helicase activity associated with the human p68 protein. Nature (London) 339:562-564.

27. Hodgman, T. C. 1988. A new superfamily of replicative proteins. Nature (London) 333:22-23.

28. Iggo, R. D., and D. P. Lane. 1989. Nuclear protein p68 is an RNA-dependent ATPase. EMBO J. 8:1827-1831.

29. Ito, H., Y. Fukuda, K. Murata, and A. Kimura. 1983. Transformation of intact yeast cells with alkali cations. J. Bacteriol. 153:163-168.

29a.Jamieson, D. Unpublished data.

29b.Johnson, D. H., and A. C. Christensen. Personal communication.

30. Jong, A., M. W. Clark, M. Gilbert, A. Oehm, and J. L. Campbell. 1987. Saccharomyces cerevisiae SSB1 protein and its relationship to nucleolar RNA binding proteins. Mol. Cell. Biol. 7:2947-2955.

31. Lane, D. P., and W. K. Hoeffler. 1980. SV40 large T shares an antigenic determinant with a cellular protein of molecular weight 68,000. Nature (London) 288:167-170.

32. Lapeyre, B., H. Bourbon, and F. Amalric. 1987. Nucleolin, the major nucleolar protein of growing eukaryotic cells: an unusual protein structure revealed by the nucleotide sequence. Proc. Natl. Acad. Sci. USA 84:1472-1476.

33. Lasko, P. F., and M. Ashburner. 1988. The product of the Drosophila gene vasa is very similar to eukaryotic initiation factor-4A. Nature (London) 335:611-617.

34. Linder, P., P. F. Lasko, M. Ashburner, P. Leroy, P. J. Nielsen, K. Nishi, J. Schnier, and P. P. Slonimiski. 1989. Birth of the D-E-A-D box. Nature (London) 337:121-122.

35. Linder, P., and P. P. Slonimski. 1989. An essential yeast protein, encoded by duplicated genes TIF1 and TIF2 and homologous to the mammalian translation initiation factor eIF-4A, can suppress a mitochondrial missense mutation. Proc. Natl. Acad. Sci. USA 86:2286-2290.

36. Michel, F., and B. F. Lang. 1985. Mitochondrial type II introns encode proteins related to the reverse transcriptases of retroviruses. Nature (London) 316:641-643.

37. Miller, A. M. 1984. The yeast MATa1 gene contains two introns. EMBO J. 3:1061-1065.

38. Miller, M. A., D. Korn, and T. S.-F. Wang. 1988. The evolutionary conservation of DNA polymerase $\alpha$. Nucleic Acids Res. 16:7961-7973.

39. Molenaar, C. M. T., L. P. Woudt, A. E. M. Jansen, W. H. Mager, R. J. Planta, D. M. Donovan, and N. J. Pearson. 1984. Structure and organisation of two linked ribosomal protein genes in yeast. Nucleic Acids Res. 12:7345-7358.
40. Moreno, S., A. Klar, and P. Nurse. 1990. An introduction to molecular genetic analysis of the fission yeast. Methods Enzymol. 194:793-823.

41. Ochs, R., M. Lischwe, P. O'Leary, and H. Busch. 1983. Localisation of nucleolar phosphoproteins B23 and C23 during mitosis. Exp. Cell Res. 146:139-149.

42. Ochs, R. L., M. A. Lischwe, E. Shen, R. E. Carroll, and H. Busch. 1985. Nucleologenesis: composition and fate of prenucleolar bodies. Chromosoma 92:330-336.

42a.Pringle, J. Personal communication.

43. Rothstein, R. J. 1983. One step gene disruption in yeast. Methods Enzymol. 101:202-211.

44. Rozen, F., I. Edery, K. Meerovitch, T. E. Dever, W. C. Merrick, and N. Sonenberg. 1990. Bidirectional RNA helicase activity of eukaryotic translation initiation factors $4 \mathrm{~A}$ and $4 \mathrm{~F}$. Mol. Cell. Biol. 10:1134-1144.

45. Russell, P., and P. Nurse. 1986. Schizosaccharomyces pombe and Saccharomyces cerevisiae: a look at yeasts divided. Cell 45:781-782.

46. Sachs, A. B., and R. W. Davis. 1990. Translation initiation and ribosomal biogenesis: involvement of a putative rRNA helicase and RPL46. Science 247:1077-1079.

47. Sambrook, J., E. F. Fritsch, and T. Maniatis. 1989. Molecular cloning: a laboratory manual. Cold Spring Harbor Laboratory, Cold Spring Harbor, N.Y.

48. Schimmang, T., D. Tollervey, H. Kern, R. Frank, and E. C. Hurt. 1989. A yeast nucleolar protein related to mammalian fibrillarin is associated with small nucleolar RNA and is essential for viability. EMBO J. 8:4015-4024.

49. Seraphin, B., M. Simon, A. Boulet, and G. Faye. 1989. Mitochondrial splicing requires a protein from a novel helicase family. Nature (London) 337:84-87.

50. Sherman, F., G. R. Fink, and J. B. Hicks. 1982. Methods in yeast genetics. Cold Spring Harbor Laboratory, Cold Spring Harbor, N.Y.

51. Siomi, H., H. Shida, S. H. Nam, T. Nosaka, M. Maki, and M. Hanataka. 1988. Sequence requirements for nucleolar localisation of human $\mathrm{T}$ cell leukaemia virus type I pX protein, which regulates viral RNA processing. Cell 55:197-209.

52. Spector, D. L., R. L. Ochs, and H. Busch. 1984. Silver staining, immunofluorescence and immunoelectron microscopic localization of nucleolar phosphoproteins B23 and C23. Chromosoma 90:139-148.

52a.Strauss, E. Personal communication

53. Warner, J. R. 1989. Synthesis of ribosomes in Saccharomyces cerevisiae. Microbiol. Rev. 53:256-271.

54. Warner, J. R. 1990. The nucleolus and ribosome formation. Curr. Opinion Cell Biol. 2:521-527.

55. Waseem, N. H., and D. P. Lane. 1990. Monoclonal antibody analysis of the proliferating cell nuclear antigen (PCNA). Structural conservation and the detection of a nucleolar form. J. Cell Sci. 96:121-129. 